\title{
Angiotensin II promotes atherosclerotic lesions and aneurysms in apolipoprotein $\mathrm{E}$-deficient mice
}

\author{
Alan Daugherty, ${ }^{1,2}$ Michael W. Manning, ${ }^{2}$ and Lisa A. Cassis ${ }^{3}$ \\ ${ }^{1}$ Division of Cardiovascular Medicine, Gill Heart Institute, \\ ${ }^{2}$ Department of Physiology, and \\ ${ }^{3}$ Division of Pharmaceutical Sciences, College of Pharmacy, University of Kentucky, Lexington, Kentucky, USA \\ Address correspondence to: Alan Daugherty, Division of Cardiovascular Medicine, Gill Heart Institute, University of Kentucky, \\ Lexington, Kentucky 40536, USA. Phone: (859) 323-3996; Fax: (859) 257-9166; E-mail: adaugh@pop.uky.edu.
}

Received for publication July 13, 1999, and accepted in revised form March 3, 2000.

Increased plasma concentrations of angiotension II (Ang II) have been implicated in atherogenesis. To examine this relationship directly, we infused Ang II or vehicle for 1 month via osmotic minipumps into mature $a p o E^{-/-}$mice. These doses of Ang II did not alter arterial blood pressure, body weight, serum cholesterol concentrations, or distribution of lipoprotein cholesterol. However, Ang II infusions promoted an increased severity of aortic atherosclerotic lesions. These Ang II-induced lesions were predominantly lipid-laden macrophages and lymphocytes; moreover, Ang II promoted a marked increase in the number of macrophages present in the adventitial tissue underlying lesions. Unexpectedly, pronounced abdominal aortic aneurysms were present in $a p o E^{-/-}$mice infused with Ang II. Sequential sectioning of aneurysmal abdominal aorta revealed two major characteristics: an intact artery that is surrounded by a large remodeled adventitia, and a medial break with pronounced dilation and more modestly remodeled adventitial tissue. Although no atherosclerotic lesions were visible at the medial break point, the presence of hyperlipidemia was required because infusions of Ang II into $\mathrm{apoE}^{+/+}$mice failed to generate aneurysms. These results demonstrate that increased plasma concentrations of Ang II have profound and rapid effects on vascular pathology when combined with hyperlipidemia, in the absence of hemodynamic influences.

J. Clin. Invest. 105:1605-1612 (2000).

\section{Introduction}

There is considerable evidence implicating a role for angiotensin II (Ang II) in the atherogenic process. The measurement of Ang II in plasma is technically difficult and fraught with experimental artifacts; thus, increased concentrations of Ang II in plasma have been inferred by the activity of the enzymes that generate this octapeptide. In humans, there is associative evidence supporting an increase in cardiovascular events with increases in the activity of renin, the rate-limiting step in Ang II generation (1). The role of Ang II in the atherogenic process has been inferred from the survival and ventricular enlargement trial that demonstrated that administration of ACE inhibitors was associated with a decrease in cardiovascular morbidity and mortality (2). Also, increases in circulating angiotensin-converting enzyme (ACE) due to a DD genotype were associated with increases in cardiovascular disease (3). In addition to increased plasma concentrations of Ang II, evidence suggests increased local production of Ang II within atherosclerotic lesions that express the necessary enzymes for Ang II synthesis including renin (4) and ACE (5). Furthermore, Ang II accumulation has been demonstrated by immunocytochemistry in human atherosclerotic lesions (6).

Inhibitors of ACE have been studied in a number of animal models of atherosclerosis, including; cynomolgus monkeys (7), minipigs (8), WHHL rabbits (9), cholesterol- fed rabbits (10-13), hamsters $(14,15)$, and $a p o E^{-/-}$mice (16). With the exception of one of these reports, all demonstrated significant reductions in the extent of atherosclerosis, consistent with a role for Ang II in the disease. However, as the specific pharmacologic properties of ACE inhibitors would influence synthesis of other autacoids in addition to Ang II, these effects of ACE inhibitors do not necessarily define an action of Ang II. Further evidence can be derived from studies in Tsukuba hypertensive mice that were created by cross breeding of transgenic animals carrying the human angiotensinogen and renin genes $(17,18)$. These mice form extensive lesions in the aortic root during feeding of diets enriched in saturated fat, cholesterol, and cholate (19).

Ang II has several potential mechanisms that may increase the atherogenic process. First, Ang II may indirectly influence the atherogenic process via hemodynamic effects resulting from increased arterial blood pressure. Marked increases in arterial blood pressure have been demonstrated to increase the severity of experimental atherosclerosis (20). Second, Ang II has been demonstrated to exert several direct effects relevant to the development of atherosclerosis including stimulation of monocyte recruitment (21), activation of macrophages (22), and enhanced oxidative stress (23), all of which have been linked to an increase in the atherogenesis process (24). These effects of Ang II would occur independent of elevations in arterial blood pressure. 
To define whether increased plasma concentrations of Ang II have a direct effect on the atherogenic process, we infused Ang II into 6-month-old $a p o E^{-/-}$mice in which the disease process was already established. Our results demonstrate that infusions of Ang II augmented the development of atherosclerosis by the formation of new lesions composed of lipid-laden macrophages and lymphocytes. Unexpectedly, Ang II also produced large abdominal aortic aneurysms. These effects of Ang II occurred independent of elevations in mean arterial pressure or changes in plasma lipid concentration and in lipoprotein cholesterol distribution.

\section{Methods}

Mice. Female C57BL/6J and apoE $E^{-/-}$mice (backcrossed $10 \times$ into a C57BL/6J background) were obtained from The Jackson Laboratories (Bar Harbor, Maine, USA). All mice were maintained under barrier conditions. Water and normal laboratory diet were available ad libitum. All procedures involving animals were approved by the Animal Care and Use Committee at the University of Kentucky.

Infusion of Ang II. Alzet osmotic minipumps (Model 2004; ALZA Scientific Products, Mountain View, California, USA) were implanted into C57BL/6J and $a p o E^{-/-}$ mice at 6 months of age. Pumps were filled either with saline vehicle or solutions of Ang II (Sigma Chemical Co., St. Louis, Missouri, USA) that delivered (subcutaneously) either 500 or $1,000 \mathrm{ng} / \mathrm{min} / \mathrm{kg}$ of Ang II for 28 days. Pumps were placed into the subcutaneous space of ketamine/xylazine anesthetized mice through a small incision in the back of the neck that was closed with surgical glue. All incision sites healed rapidly without the need for any medication.

Determination of blood pressure. Systolic blood pressure was obtained on a weekly basis in ketamine/xylazine anesthetized mice using a tail cuff apparatus coupled to a PC-based data acquisition system (RTBP1007; Kent Scientific, Litchfield, Connecticut, USA). A minimum of three measurements were obtained from each mouse. At the termination of the experiment, mean arterial pressure was measured in anesthetized mice via a femoral artery catheter coupled to the data acquisition system.

Lipids and lipoprotein characterization. Serum total cholesterol and triglyceride concentrations were determined with enzymatic assay kits (Wako Chemical Co., Richmond, Virginia, USA). Lipoprotein cholesterol distributions were evaluated in individual serum samples $(50 \mu \mathrm{L})$ from four mice in each group after fractionation by fast protein liquid chromatography (FPLC) gel filtration (Pharmacia LKB Biotechnology, Uppsala, Sweden) on a single Superose 6 column (25). Fractions were collected and cholesterol concentrations were determined with an enzymatic-based assay kit (Wako Chemical Co.).

Quantification of atherosclerotic lesions. Aortic tissue was removed from the ascending aorta to the ileal bifurcation and placed in freshly prepared $4 \%$ paraformaldehyde in PBS overnight at room temperature. After tissue fixation, adventitial tissue was carefully removed.
The intimal surface was exposed by a longitudinal cut through the inner curvature of the aortic arch that extended down the whole length of the aortic tree. To permit the arch region to be laid out flat, the greater curvature was cut down to the level of the left subclavian artery. The tissue was laid out on a black background, and an image of the aorta was recorded.

To quantify the extent of intimal surface covered by grossly discernible lesions, image analysis was performed with SigmaScan (SPPS Inc., Chicago, Illinois, USA). The extent of atherosclerotic lesions was quantified in the arch, thorax, and abdominal regions. The regions were defined as follows: (a) arch, from the ascending arch to 4 $\mathrm{mm}$ distal to the left subclavian artery; (b) thorax, from the arch to the last intercostal artery branch; and (c) from the thorax to the branch of the ileal bifurcation. The percent of intimal area covered by lesions was quantified by two observers. There was routinely less than a 5\% difference between the determinations of the two observers.

Histological and immunocytochemical characterization of atherosclerotic lesions. Aortic tissue was characterized either at the root or in the abdominal section. For aortic root analysis, mice were perfused with PBS via a cannula placed in the left ventricle, with fluid drained from a severed right atria. The hearts from PBS-perfused mice were severed from the aorta at the base, embedded in OCT, and frozen. Abdominal sections of aorta were fixed overnight in 4\% paraformaldehyde in PBS before embedding in OCT. Serial $(10 \mu \mathrm{m})$ sections from both regions were mounted on Fisher MicroProbe slides (Fisher Scientific Co., Pittsburgh, Pennsylvania, USA). Elastin was identified in selected sections with Verhoeff stains. Collagen and muscle cells were identified by Gimori staining. Neutral lipids were stained with Oil Red O.

For immunocytochemistry, sections were fixed by a 5 -minute incubation in chilled ethanol. Endogenous peroxidases were quenched by incubating sections in $3 \% \mathrm{H}_{2} \mathrm{O}_{2}$ in methanol. Sections were subsequently blocked with a $1 \%$ solution of the sera from the species

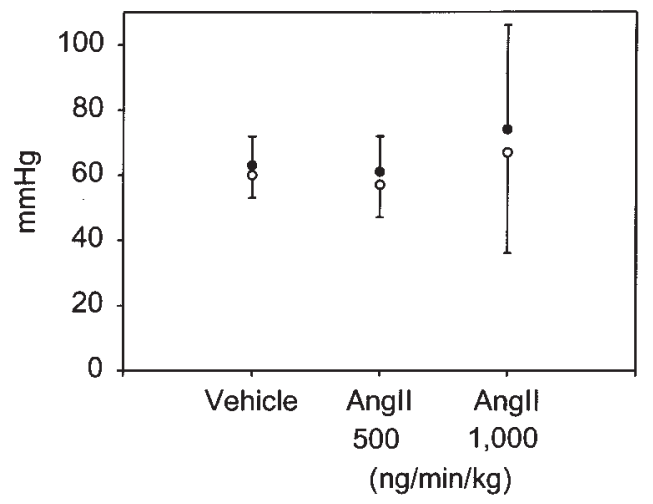

Figure 1

Arterial blood pressure determined using a catheter in the femoral artery of anesthetized apo $\mathrm{E}^{-/-}$mice. Mice were anesthetized after 28 days of infusion of vehicle or the stated dose of Ang II. Points represent the mean of at least seven observations, and bars represent SEM. 


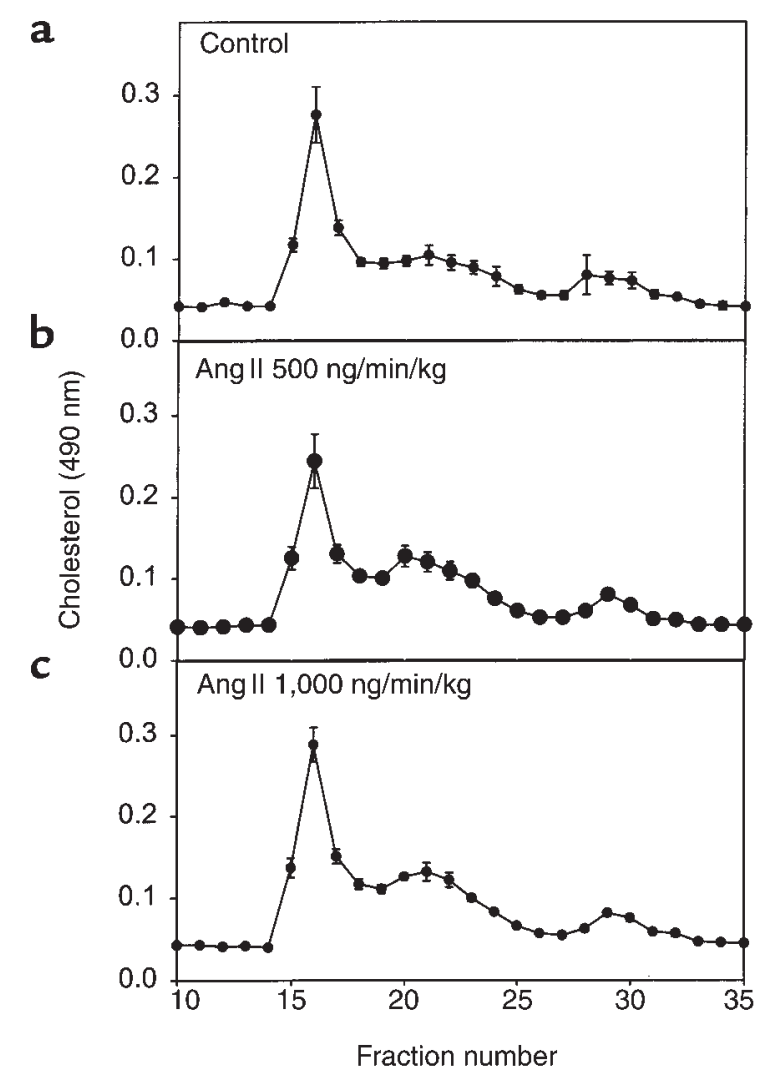

Figure 2

Distribution of lipoprotein cholesterol in serum during infusion of vehicle (a), Ang II at $500 \mathrm{ng} / \mathrm{min} / \mathrm{kg}$ (b), or Ang II at 1,000 ng/min/ $\mathrm{kg}$ (c). Serum $(50 \mu \mathrm{L})$ was resolved with a Sepharose $6 \mathrm{~B}$ column, and cholesterol content of fractions was analyzed with commercially available assay kits. Points represent the mean of five chromatographic separations that were performed on serum from individual mice, and bars represent SEM.

used to generate the secondary antibody. Macrophages were detected using a polyclonal antibody $(1: 10,000$ dilution; Accurate Chemical \& Scientific Corp., Westbury, New York, USA) and lymphocytes were detected using a mAb against CD90 (1:30 dilution; BioSource International, Camarillo, California, USA). Primary antisera were incubated for 10 minutes at $37^{\circ} \mathrm{C}$, followed by an incubation of a secondary biotinylated antibody under the same conditions, and a complex of avidin-biotin-horseradish peroxidase (Vector Laboratories, Burlingame, California, USA). Immunoreactivity was visualized by incubation with the red chromagen, aminoethyl carbozole. Nuclei were visualized by counterstaining with aqueous hematoxylin.

Statistical analysis. The null hypothesis for the variables measured in the groups was initially tested by ANOVA. If a group difference was noted, post hoc testing was performed using either parametric testing for multiple groups if the data did not fit the constraints of this form of analysis. Otherwise they were tested using Wilcoxon rank sum tests. All statistical analyses were performed with SigmaStat (Jandel Scientific, San Rafael, California, USA). Data are presented as means \pm SEM.

\section{Results}

Ang II infusions had no effects on peripheral parameters that influence atherogenesis. We have previously infused Ang II at a dose of $200 \mathrm{ng} / \mathrm{min} / \mathrm{kg}$ into rats and have demonstrated increases in systolic pressure (by $40 \mathrm{mmHg}$ ), development of cardiac hypertrophy, and a decrease in body weight (26). In contrast, results from preliminary studies indicated that mice required substantially higher doses of Ang II to achieve any discernible effect (data not shown). Therefore, we chose doses of 500 and 1,000 $\mathrm{ng} / \mathrm{min} / \mathrm{kg}$ of Ang II, which were infused over 28 days in 6-month-old $a p o E^{-/-}$mice fed a normal diet. The Ang II infusions were initiated in apo $E^{-/-}$mice at an interval of modest atherosclerotic lesion development (27).

Infusion of Ang II (500 or $1,000 \mathrm{ng} / \mathrm{min} / \mathrm{kg}$ ) did not significantly alter body weight (Table 1 ; ref. 26). Arterial blood pressure was measured on anesthetized mice at weekly intervals after the start of Ang II infusion. There was no significant change in systolic blood pressure in Ang II infused mice compared with vehicle-infused controls throughout the experimental protocol (data not shown). On day 28 of Ang II infusion, mice were anesthetized and mean arterial pressure was obtained via a catheter placed in the left femoral artery. Systolic, diastolic, and mean arterial pressure was not significantly different in the groups infused with Ang II compared with vehicle controls (Figure 1). Moreover, infusion of Ang II tended to reduce serum concentrations of both cholesterol and triglycerides, but neither of these changes reached statistical significance (Table 1). In addition, Ang II infusion did not change the distribution of cholesterol within lipoprotein fractions as determined by size exclusion chromatography (Figure 2).

Ang II increases the extent of atherosclerosis by causing newly formed lesions composed of lipid-laden macrophage and lymphocytes. The extent of atherosclerosis was measured on the aortic intimal surface as described previously (28). The abdominal segment was excluded from this analysis because of the appearance of aneurysms as described later here. There was extensive atherosclero-

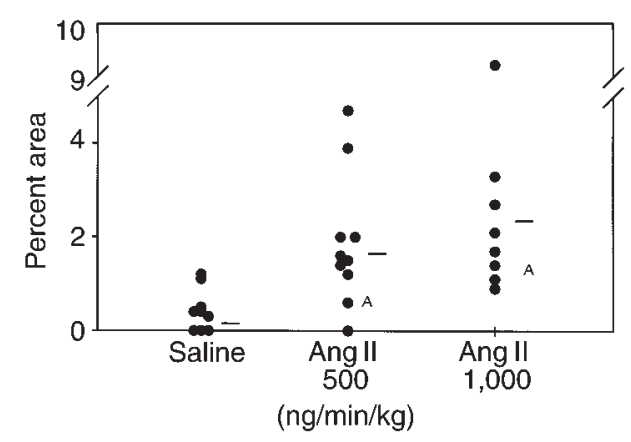

\section{Figure 3}

Percent of intimal area covered by grossly discernible atherosclerotic lesions in the thoracic region. Circles represent the values for individual animals, and bars are the means for the groups. Infusion of Ang II significantly increased the percent of lesion area in the thoracic aorta. AStatistical difference of $P>0.05$ from the control group using a Wilcoxon's rank sum test. 


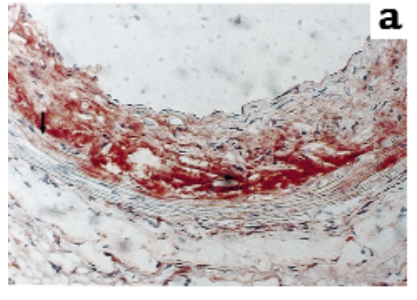

a

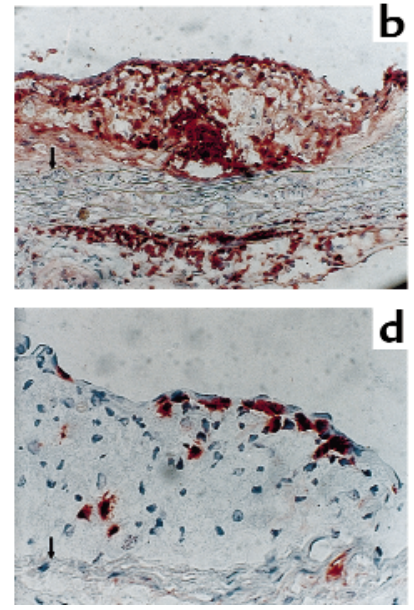

\section{Figure 4}

Characteristics of atherosclerotic lesions from vehicle-infused apoE $\mathrm{E}^{-1-}$ mice (a) and Ang II-infused mice (b-d). Tissues were immunostained for the presence of macrophages $(\mathbf{a}-\mathbf{c})$ using an antiserum purchased from Accurate Chemical and Scientific Corp. (1:10,000 dilution). Lymphocytes were immunostained (d) using a CD90 antibody from BioSource International (1:30 dilution). Tissue sections were counterstained with hematoxylin. a-c, $\times 200 ; \mathbf{d} \times 400$. An arrow indicates the medial-intimal boundary.

sis in the arch of all groups of apoE $E^{-/-}$mice, as may be expected for the age of the mice. The relatively brief infusion of Ang II did not significantly change the extent of this established disease (data not shown). In contrast to the arch region, apo $E^{-/-}$mice infused with vehicle had either none or very few lesions present in the thoracic aorta. In this region, Ang II promoted a significant increase in the extent of discernible atherosclerotic lesions in the thoracic aorta (Figure 3). Although the mean value for the lesion quantification was higher in the group infused with 1,000 compared with $500 \mathrm{ng} / \mathrm{min} / \mathrm{kg}$ of Ang II, the difference did not attain statistical significance. In the group infused with the higher dose $(1,000 \mathrm{ng} / \mathrm{min} / \mathrm{kg})$ of Ang II, several of the mice had many small lesions dispersed randomly throughout the thoracic aorta, consistent with Ang II (Figure 4, b-d) initiating the development of lesions. Immunocytochemical analysis of arterial tissue from vehicle-treated mice demonstrated that lesions had cores that diffusely immunostained for macrophages, although there was a low number of nuclei in this region (Figure 4a). These characteristics of the tissue would be consistent with the presence of nonviable cells in the core region. Cells in the more abluminal aspect of the lesion had a smooth muscle cell-like appearance. Three major differences were observed in mice infused with Ang II (Figure 4, b-d). One was the extent of medial hypertrophy seen after Ang II infusion. Second was the pronounced presence of macrophages in the adventitia underlying lesions (Figure 4, a versus b). Macrophage immunostaining in these regions was characterized by intense chromagen development in cells that did not have overt lipid dep- osition. Many of these cells were present at the boundary of the atherosclerotic intima and media. Third was the presence of new lesions that appeared to have formed on top of established lesions (Figure 4c). These were characterized by lipid-laden cells that immunostained with the antimacrophage antibody. In addition, there was a large number of lymphocytes present on the luminal aspect of lesions (Figure 4d).

Ang II infusion promotes the development of abdominal aortic aneurysms. During removal of the aortas, it was noted that there was substantial adventitial tissue present in the abdominal area of the aorta in some of the apo $E^{-/-}$ mice infused with Ang II. A representative aorta from an $a p o E^{-/-}$mouse receiving Ang II compared with saline vehicle controls is illustrated in Figure 5. The region in the abdominal aorta from an Ang II-infused mouse was markedly increased in size; moreover, the tissue encompassing this region was resistant to the dissection process typically used to remove adventitial tissue. The bulbous aortic abdominal shape illustrated in Figure 5 occurred in $20 \%$ and $33 \%$ of mice in the groups infused with 500 and $1,000 \mathrm{ng} / \mathrm{min} / \mathrm{kg}$ of Ang II, respectively. A blood clot was present within the greatly expanded adventitial tissue, and the neovasculature was present on the outer surface. In contrast, in mice infused with vehicle, adventitial tissue was easily removed from the aorta.

Several of the aortic aneurysms were sectioned at 10 $\mu \mathrm{m}$ throughout the entire bulbous area of the abdominal aorta. These sections revealed two regions of dis-

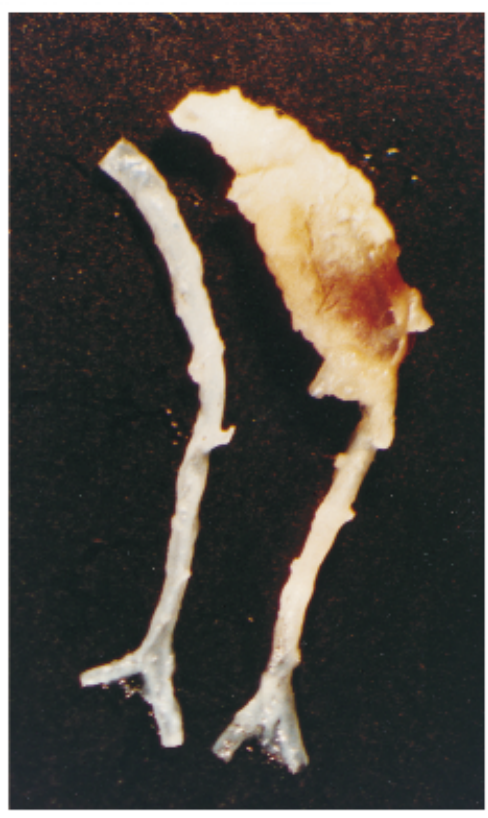

Figure 5

An example of the aneurysms formed in the abdominal aorta of apoE $\mathrm{E}^{-/-}$mice infused with Ang II. The aortic segments shown are from approximately the last intercostal branch to the ileal bifurcation. The aorta on the right is an example from an a $\mathrm{poE}^{-/-}$mouse infused with Angll $(1,000 \mathrm{ng} / \mathrm{min} / \mathrm{kg})$ for 28 days. The aorta on the left is an example from an age- and gender-matched apoE-/- mouse infused with vehicle for the same interval. 
Table 1

Body weight and serum lipid concentration in apoE-/- mice infused with either vehicle or the stated doses of Ang II for 28 days via osmotic pumps

$\begin{array}{lccc}\text { Group } & \begin{array}{c}\text { Body weight } \\ (\mathrm{g})\end{array} & \begin{array}{c}\text { Serum cholesterol } \\ \text { concentration }(\mathrm{mg} / \mathrm{dL})\end{array} & \begin{array}{c}\text { Serum triglyceride } \\ \text { concentration }(\mathrm{mg} / \mathrm{dL})\end{array} \\ \text { Control } & 25.3 \pm 0.7 & 330 \pm 76 & 45 \pm 5 \\ \text { Ang II } 500 \mathrm{ng} / \mathrm{min} / \mathrm{kg} & 24.3 \pm 0.4(\mathrm{NS}) & 211 \pm 6(\mathrm{NS}) & 27 \pm 4(\mathrm{NS}) \\ \text { Ang II } 1,000 \mathrm{ng} / \mathrm{min} / \mathrm{kg} & 24.3 \pm 0.5(\mathrm{NS}) & 258 \pm 21(\mathrm{NS}) & 34 \pm 7(\mathrm{NS})\end{array}$

Values represent the mean \pm SEM; $n=8-10$ for all groups. NS, not significant compared with controls.

tinct characteristics. One region had intact elastin layers in the media that were associated with pronounced remodeling in the adventitial space (Figure 6a). The cross-sectional area of the lumen of the abdominal aorta of these sections was similar to that of tissues of the same region from mice not infused with Ang II. This region of the aneurysm usually contained a blood clot surrounded by extracellular matrix that had a prominent collagen content (Figure 6b). Neutral lipids, defined by Oil Red $\mathrm{O}$ staining, marginated to the outer boundaries of the remodeled tissue (Figure 6c). Immunostaining for macrophages also tended to be marginated to the outer boundaries, although some diffuse immunostaining was present in much of the remodeled area (Figure $6 \mathrm{~d}$ ). The other region of the aneurysm was characterized by a complete medial break that resulted in marked dilation of the lumen (Figure 6, e and f). In this region, there was thinner adventitial area that had a relatively greater component of neutral lipids and macrophages. In the four aneurysms that were sequentially sectioned, small atherosclerotic lesions were observed; however, lesions were not at the site of the abdominal aortic segments containing the medial breaks.

Equivalent doses of Ang II do not cause vascular pathology in apo $E^{+/+}$mice. To determine whether the Ang II-induced promotion of atherosclerotic lesions and aneurysm formation required the hyperlipidemic state present in apo $E^{-/-}$mice, Ang II infusions (500 and 1,000 $\mathrm{ng} / \mathrm{min} / \mathrm{kg}$ ) were performed in $a p o E^{+/+}$mice of the equivalent strain; $\mathrm{C} 57 \mathrm{BL} / 6 \mathrm{~J}$. As with the apoE $E^{-/-}$mice, systolic blood pressure was measured weekly using a tail cuff and was not significantly altered throughout Ang II infusion (data not shown). Systolic and diastolic arterial measurements obtained via a femoral artery catheter on day 28 of Ang II infusion also failed to demonstrate any significant change (Table 2). As may be expected, there were no discernible atherosclerotic lesions in these normolipidemic C57BL/6J mice infused with either of the doses of Ang II. Furthermore, no aneurysms were observed. However, Ang II promoted medial hypertrophy as already described here in the $a p o E^{-1-}$ mice.

\section{Discussion}

This study was designed to determine whether increases in circulating plasma concentrations of Ang II were associated with an increase in the extent of atherosclerosis. All experiments were performed in $a p o E^{-/-}$mice that develop hyperlipidemia and relatively complex atherosclerotic lesions when fed normal laboratory diets $(29,30)$. In agreement with previous studies, the most prominent regions for lesion development in $a p o E^{-/-}$mice used in this study at 7 months of age were the aortic root and arch (27). Small lesions were present near the renal arteries, whereas the majority of the thoracic aorta was relatively lacking in lesions even at intercostal branch points. After relatively short intervals (28 days) of Ang II infusion, there were several changes in vascular pathology including an increase in the extent of atherosclerosis, a change in the nature of

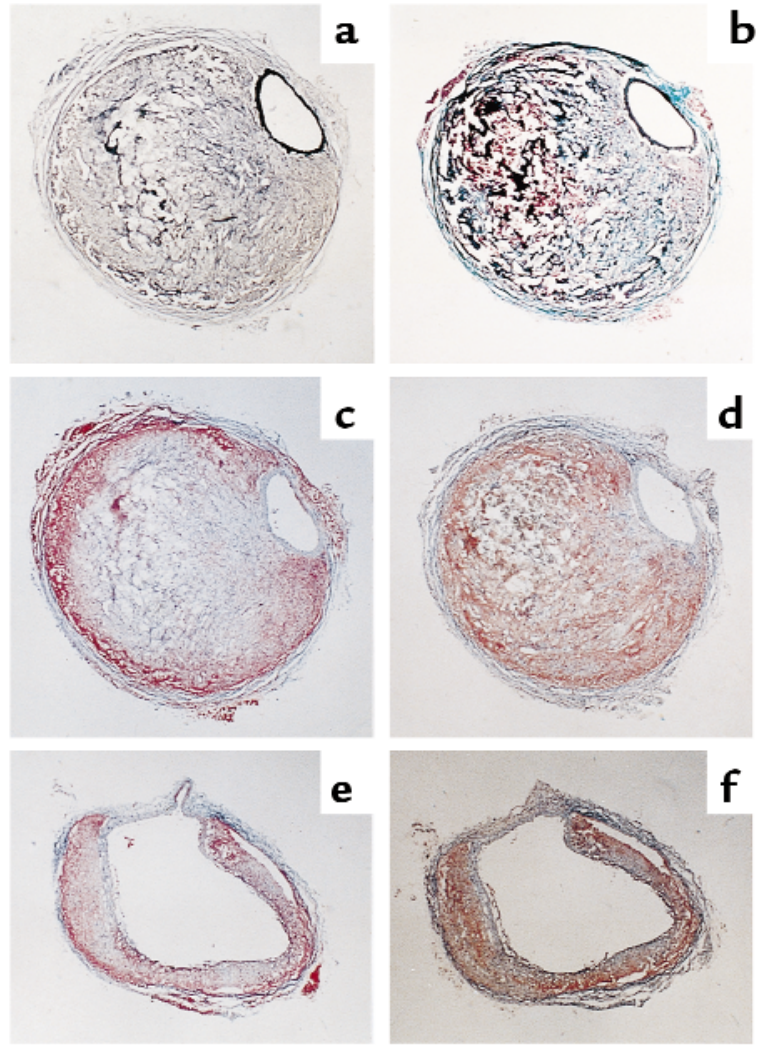

Figure 6

Characteristics of aneurysmal tissue in the abdominal aorta of apoE-/- mice infused with Ang II. Sections are stained or immunostained with the following methods: (a) Verhoeff; (b) Gimori; (c) Oil Red O; (d) presence of macrophages using antisera from Accurate Chemical and Scientific Corp. (dilution 1:10,000) and counterstained with hematoxylin; (e) Oil Red O; and (f) presence of macrophages as in d. $\times 200$. 
Table 2

Systolic and diastolic arterial pressure measured using a femoral artery catheter in groups of wild-type C57BL/ 6 mice infused with either vehicle or the stated dose of Ang II for 28 days via osmotic pump

\begin{tabular}{lcc}
\hline Group & $\begin{array}{c}\text { Systolic arterial } \\
\text { pressure } \\
(\mathrm{mmHg})\end{array}$ & $\begin{array}{c}\text { Diastolic arterial } \\
\text { pressure } \\
(\mathrm{mmHg})\end{array}$ \\
Control & $85 \pm 10$ & $78 \pm 10$ \\
Ang II $500 \mathrm{ng} / \mathrm{min} / \mathrm{kg}$ & $56 \pm 17(\mathrm{NS})$ & $48 \pm 17$ (NS) \\
Ang II $1,000 \mathrm{ng} / \mathrm{min} / \mathrm{kg}$ & $53 \pm 9(\mathrm{NS})$ & $40 \pm 7$ (NS)
\end{tabular}

Values represent the mean \pm SEM; $n=5$ for all groups. NS, not significant compared with controls.

lesions and adventitial tissue underlying lesions, and the formation of large abdominal aortic aneurysms. These vascular alterations occurred in the absence of changes in plasma cholesterol concentration and distribution and independent of Ang II-mediated increases in arterial blood pressure. The promotion of vascular pathology required the hyperlipidemic state, as atherosclerosis and aneurysm formation were not observed in strain-matched $a p o E^{+/+}$mice.

Although Ang II is a potent hypertensive agent, we were unable to detect a sustained increase in arterial blood pressure over a 4-week period of Ang II infusion at doses previously demonstrated to elevate blood pressure in rats chronically (26). Measurements of systolic pressure were performed in anesthetized mice using a tail cuff system. Although this technique has been used previously to define blood pressure in conscious mice $(31,32)$, a substantial interval of training of conscious mice is required before stable measurements are obtained (33). An additional barrier prohibiting conscious measurements of systolic pressure in the present study included the use of C57BL/6 mice, which are known for their high locomotor activity and resistance to restraint (34). To validate systolic pressure measurements using a tail cuff, we measured arterial pressure in anesthetized mice on the final day of the study through a catheter placed in the femoral artery. Measurements of mean arterial pressure obtained in $a \mathrm{poE}^{-/-}$mice were in agreement with previously published values (35). Measurements obtained by femoral artery catheter confirmed that Ang II infusion did not increase blood pressure in apo $E^{-/-}$mice, in agreement with results obtained by the tail cuff method. Statistical analysis of these data did not fulfill the constraints of equivalence variance and normal distribution to be analyzed by parametric statistics in the post hoc ANOVA tests. Consequently, we used the Wilcoxon rank sum test, which is considerably less sensitive than parametric analysis. Using this test, there were no statistically significant changes. Potential mechanisms contributing to the lack of a hypertensive effect of Ang II in mice include a high endogenous Ang II concentration due to the presence of two renin genes (36), rapidly developing tolerance to Ang II (37), compensatory cardiovascular reflexes elicited in response to Ang II, or regulation of Ang II recep- tors after chronic Ang II exposure (38). Taken together, our results demonstrate that the observed effects of Ang II infusion on vascular pathology were unrelated to elevations of arterial blood pressure.

Ang II promoted several changes in the cellular characteristics of aortic tissue and atherosclerotic lesions. Despite a lack of effect of Ang II on arterial blood pressure, medial hypertrophy was noted in the aortas of both apoE $E^{-/-}$and $a p o E^{+/+}$mice. Nonpressor doses of Ang II have been previously shown to promote hypertrophy (39). Ang II also provoked marked proinflammatory responses in the perimedial area, manifest as an accumulation of macrophages at the external elastic lamina. This effect is consistent with a chemoattractant property of Ang II (40). The most marked change in atherogenesis was the formation of new lesions that were adjacent to the mature fibrolipid lesions that had formed in these 7-month-old $a p o E^{-/-}$mice. The most prominent feature of these newly formed lesions was lipid-laden cells that immunostained for macrophages. Unlike the core region of established lesions, these newly formed lesions contained many nuclei. Another prominent feature of the lesions that formed during Ang II infusion was the presence of a large number of lymphocytes; a cell type that has a hypothesized, although unproved, role in atherogenesis $(41,42)$. We have previously reported that the relative number of $\mathrm{T}$ lymphocytes decreases as lesions evolve in $a p o E^{-/-}$mice, which is consistent with the presence of the large number of this cell type in these newly formed lesions (43).

There are several potential mechanisms by which Ang II could augment the atherogenic process. Ang II is thought to increase atherosclerosis through hemodynamic effects, and its attendant changes in shear stress could influence the atherogenic process (44). Indeed, there is accelerated lesion formation in transgenic mice with hypertension resulting from an activated renin angiotensin system (19). These mice had marked increases in systolic arterial blood pressure that accompanied the increase in the extent of Oil Red O-stained area in the aortic root. In the present study, we were unable to detect any sustained increase in arterial pressure after chronic Ang II infusion, suggesting that hemodynamic influences of Ang II were not paramount in Ang II augmentation of the atherogenic process.

A number of direct effects of Ang II have been suggested to contribute to the atherogenic process including stimulation of monocyte/macrophage recruitment and activation $(21,45)$. A potential mediator of this activity is monocyte chemoattractant protein-1 (MCP1 ; refs. 46, 47). There is considerable evidence supporting a role for MCP-1 in atherogenesis. MCP-1 has the ability to chemoattract macrophages (48) and lymphocytes (49), both of which are prominent cell types in atherosclerotic lesions $(41,50)$. Also, MCP-1 protein is present in atherosclerotic lesions from both humans and experimental animals (51). Definitive evidence supporting a role for this cytokine has come from genetically engineered mice that are deficient in MCP-1 and 
exhibit reduced severity of atherosclerosis when crossbred to LDL receptor ${ }^{-/-}$mice (52) or apolipoprotein B transgenic mice (53). Furthermore, deficiency of the major MCP-1 receptor, CCR-2, reduced the extent of atherosclerosis in apoE $E^{-/-}$mice (54). Previous studies have demonstrated that Ang II promotes the elaboration of MCP-1 from endothelial cells and smooth muscle cells (46). There have been no studies demonstrating an effect of Ang II on the release of MCP-1 from macrophages, even though this cell type is the major loci for accumulation of MCP-1 in lesions (51). However, the recent demonstration of Ang II activating the transcription factor NF-B in monocytes is consistent with an ability to promote secretion of this chemokine (55). In Ang II-infused mice, we observed newly formed lesions, some of which were located on top of existing lesions that consisted of lipid-laden macrophages and lymphocytes. These characteristics are consistent with Ang II-promoting MCP-1 expression.

Aneurysms of the abdominal aorta represent a significant cardiovascular risk. Despite the common occurrence of this vascular disease, the mechanism(s) that leads to the pathology remains undefined (56). Aneurysms of the abdominal aorta have been demonstrated previously in apo $E^{-/-}$mice $(57,58)$. The formation of aneurysms in apo $E^{-/-}$mice was suggested to relate to the activity of metalloelastase or metalloprotease-12 (58). However, aneurysms previously observed in the $a p o E^{-/-}$model encompassed modest dilations that did not produce total disruption of the media and did not exhibit pathology similar to that seen in humans $(57,58)$.

Aneurysms and aortic rupture have been noted in hypertensive mice that overproduce Ang II, although only when mice were placed on high sodium chloride containing water (59). There are some clinical and experimental links of Ang II to aneurysm formation. For example, gene polymorphism of ACE has also been associated with the development of aneurysms (60). Experimentally, specific strains of rats exhibit rupture of the internal elastic lamina by a process that is abrogated by ACE inhibitors (61). Also, salt loading the Tsukuba hypertensive mouse lead to rupture of the aorta at the arch and abdominal sites (59). The changes in vascular pathology in Tsukuba mice during salt loading occurred independent of changes in arterial blood pressure. However, these previously observed aortic aneurysms do not provide the complex tissue remodeling in the adventitia that are characteristic of the human disease. In contrast, infusion of Ang II into $a p o E^{-/-}$mice promoted the appearance of blood clots and tissue remodeling surrounding an area of marked adventitial hypertrophy. Pronounced luminal dilations were also present. Of note, the complex morphology of the aneurysms formed in response to Ang II occurred in the absence of a measurable increase in blood pressure.

We performed sequential sectioning through the entire aneurysm of several abdominal aortae. In no case were we able to demonstrate the presence of an atherosclerotic lesion at or close to the site of the medial break. However, it is possible that a lesion present at the aneurysm site may have been resorbed into the perimedial tissue after the rupture. Although no atherosclerotic lesions could be detected at the site of media break, no aneurysms were detected when the identical study was performed in the background strain to the apo $E^{-/-}$mice; C57BL/6. ApoE has many biologic properties in addition to its effects on plasma lipoprotein metabolism (62). However, it appears that the hyperlipidemic state is augmented with the responsiveness of Ang II, as we have also noted the presence of aortic abdominal aneurysms in LDL receptor ${ }^{-/}$mice fed a saturated-fat-and-cholesterol-containing diet (63).

In conclusion, we have demonstrated that short intervals of Ang II infusion into apoE $E^{-/-}$mice with established atherosclerosis leads to augmented lesion formation and the unexpected development of abdominal aorta aneurysms. Further studies will define the mechanism by which Ang II exerts these effects.

\section{Acknowledgments}

We are grateful for the excellent technical assistance of A. Block, M. Drawdy, P. Ravishankar, and D. Rateri.

1. Alderman, M.H., et al. 1991. Association of the renin-sodium profile with the risk of myocardial infarction in patients with hypertension. $N$. Engl. J. Med. 324:1098-1104.

2. Pfeffer, M.A., et al. 1992. Effect of captropril on mortality and morbidity in patients with left ventricular dysfunction after myocardial infarction. N. Engl. J. Med. 327:669-677.

3. Samani, N.J., Thompson, J.R., O’Toole, L., Channer, K., and Woods, K.L. 1996. A meta-analysis of the association of the deletion allele of the angiotensin-converting enzyme gene with myocardial infarction. Circulation. 94:708-712.

4. Iwai, N., Inagami, T., Ohmichi, N., and Kinoshita, M. 1996. Renin is expressed in rat macrophage/monocyte cells. Hypertension. 27:399-403.

5. Diet, F., et al. 1996. Increased accumulation of tissue ACE in human atherosclerotic coronary artery disease. Circulation. 94:2756-2767.

6. Potter, D.D., Sobey, C.G., Tompkins, P.K., Rossen, J.D., and Heistad, D.D. 1998. Evidence that macrophages in atherosclerotic lesions contain angiotensin II. Circulation. 98:800-807.

7. Aberg, G., and Ferrer, P. 1990. Effects of captopril on atherosclerosis in cynomolgus monkeys. J. Cardiovasc. Pharmacol. 15(Suppl.):S65-S72.

8. Charpiot, P., et al. 1993. ACE inhibition with perindopril and atherogenesis-induced structural and functional changes in minipig arteries. Arterioscler. Thromb. 13:1125-1138.

9. Chobanian, A.V., Haudenschild, C.C., Nickerson, C., and Drago, R. 1990. Antiatherogenic effect of captopril in the Watanabe heritable hyperlipidemic rabbit. Hypertension. 15:327-331.

10. Campbell, J.H., Fennessy, P., and Campbell, G.R. 1992. Effect of perindopril on the development of atherosclerosis in the cholesterol-fed rabbit. Clin. Exp. Pharmacol. Physiol. 19:13-17.

11. Schuh, J.R., Blehm, D.J., Frierdich, G.E., McMahon, E.G., and Blaine, E.H. 1993. Differential effects of renin-angiotensin system blockade on atherogenesis in cholesterol-fed rabbits. J. Clin. Invest. 91:1453-1458.

12. Finta, K.M., et al. 1993. Ramipril prevents impaired endotheliumdependent relaxation in arteries from rabbits fed an atherogenic diet. Atherosclerosis. 100:149-156.

13. Hoshida, S., et al. 1997. Vascular angiotensin-converting enzyme activity in cholesterol-fed rabbits: effects of enapapril. Atherosclerosis. 130:53-59.

14. Kowala, M.C., et al. 1998. Enhanced reduction of atherosclerosis in hamsters treated with pravastatin and captopril: ACE in atheromas provides cellular targets for captopril. J. Cardiovasc. Pharmacol. 32:29-38.

15. Kowala, M.C., Recce, R., Beyer, S., and Aberg, G. 1995. Regression of early atherosclerosis in hyperlipidemic hamsters induced by fosinopril and captopril. J. Cardiovasc. Pharmacol. 25:179-186.

16. Hayek, T., Attias, J., Smith, J., Breslow, J.L., and Keidar, S. 1998. Antiatherosclerotic and antioxidative effects of captopril in apolipoprotein E-deficient mice. J. Cardiovasc. Pharmacol. 31:540-544.

17. Fukamizu, A., et al. 1989. Tissue-specific expression of the human renin gene in transgenic mice. Biochem. Biophys. Res. Commun. 165:826-832. 
18. Takahashi, S., et al. 1991. Expression of the human angiotensinogen gene in transgenic mice and transfected cells. Biochem. Biophys. Res. Com mun. 180:1103-1109.

19. Sugiyama, F., et al. 1997. Acceleration of atherosclerotic lesions in transgenic mice with hypertension by the activated renin-angiotensin system. Lab. Invest. 76:835-842.

20. Chobanian, A.V., and Alexander, R.W. 1996. Exacerbation of atherosclerosis by hypertension. Potential mechanisms and clinical implications. Arch. Intern. Med. 156:1952-1956.

21. Kim, J.A., Berliner, J.A., and Nadler, J.L. 1996. Angiotensin II increases monocyte binding to endothelial cells. Biochem. Biophys. Res. Commun. 226:862-868

22. Yanagitani, Y., et al. 1999. Angiotensin II type 1 receptor-mediated peroxide production in human macrophages. Hypertension. 33:335-339.

23. Keidar, S. 1998. Angiotensin, LDL peroxidation and atherosclerosis. Life Sci. 63:1-11.

24. Daugherty, A., and Roselaar, S.E. 1995. Lipoprotein oxidation as a mediator of atherogenesis: insights from pharmacological studies. Cardiovasc. Res. 29:297-311.

25. Cole, T.G., Kitchens, R., Daugherty, A., and Schonfeld, G. 1990. An improved method for separation of triglyceride-rich lipoproteins by FPLC. Pharmacia Biocommunique. 4:4-6.

26. Cassis, L.A., Marshall, D.E., Fettinger, M.J., Rosenbluth, B., and Lodder, R.A. 1998. Mechanisms contributing to angiotensin II regulation of body weight. Am. J. Physiol. 274:E867-E876.

27. Nakashima, Y., Plump, A.S., Raines, E.W., Breslow, J.L., and Ross, R. 1994. ApoE-deficient mice develop lesions of all phases of atherosclerosis throughout the arterial tree. Arterioscler. Thromb. 14:133-140.

28. Daugherty, A., et al. 1997. The effects of total lymphocyte deficiency on the extent of atherosclerosis in apolipoprotein E-/- mice. J. Clin. Invest. 100:1575-1580.

29. Zhang, S.H., Reddick, R.L., Piedrahita, J.A., and Maeda, N. 1992. Spontaneous hypercholesterolemia and arterial lesions in mice lacking apolipoprotein E. Science. 258:468-471.

30. Plump, A.S., et al. 1992. Severe hypercholesterolemia and atherosclerosis in apolipoprotein-E-deficient mice created by homologous recombination in ES cells. Cell. 71:343-353.

31. Oliverio, M.I., et al. 1997. Angiotensin II responses in AT1a receptor-deficient mice: a role for AT1b receptors in blood pressure regulation. Am. J. Physiol. 272:F515-F520.

32. Shesely, E.G., et al. 1996. Elevated blood pressures in mice lacking endothelial nitric oxide synthase. Proc. Natl. Acad. Sci. USA. 93:13176-13181.

33. Johns, C., Gavras, I., Handy, D.E., Salomao, A., and Gavras, H. 1996. Models of experimental hypertension in mice. Hypertension. 28:1064-1069.

34. Davis, W.M., and King, W.T. 1967. Pharmacogenetic factor in the convulsive responses of mice to flurothyl. Experientia. 23:214-215.

35. Davisson, R.L., et al. 1997. Complementation of reduced survival, hypotension, and renal abnormalities in angiotensinogen-deficient mice by the human renin and human angiotensinogen genes. J. Clin. Invest. 99:1258-1264.

36. Bertaux, F., et al. 1997. Normotensive blood pressure in mice with a disrupted renin Ren-1d gene. Transgenic Res. 6:191-196.

37. Bing, J., and Poulsen, K. 1979. In mice aggressive behavior provokes vast increase in plasma renin concentration, causing only slight, if any, increase in blood pressure. Acta Physiol. Scand. 105:64-72.

38. Wang, D.H., Du, Y., and Yao, A. 1996. Regulation of the gene-encoding angiotensin II receptor in vascular tissue. Microcirculation. 3:237-239.

39. Su, E.J., Lombardi, D.M., Siegal, J., and Schwartz, S.M. 1998. Angiotensin II induces vascular smooth muscle cell replication independent of blood pressure. Hypertension. 31:1331-1337.

40. Jardine, A.G. 1995. Angiotensin II and glomerulonephritis. J. Hypertens. 13:487-493.

41. Daugherty, A. 1997. Lymphocytes in atherosclerotic lesions: bystanders or active participants. Atherosclerosis ID Research Alert. 9:395-400.

42. Stemme, S., and Hansson, G.K. 1994. Immune mechanism in athero- sclerosis Coron. Artery Dis. 5·216-222.

43. Roselaar, S.E., Kakkanathu, P.X., and Daugherty, A. 1996. Lymphocyte populations in atherosclerotic lesions of ApoE -/- and LDL receptor -/mice: decreasing density with disease progression. Arterioscler. Thromb. Vasc. Biol. 16:1013-1018

44. Traub, O., and Berk, B.C. 1998. Laminar shear stress: mechanisms by which endothelial cells transduce an atheroprotective force. Arterioscler. Thromb. Vasc. Biol. 18:677-685.

45. Hahn, A.W., Jonas, U., Buhler, F.R., and Resink, T.J. 1994. Activation of human peripheral monocytes by angiotensin II. FEBS Lett. 347:178-180.

46. Chen, X.L., Tummala, P.E., Olbrych, M.T., Alexander, R.W., and Medford, R.M. 1998. Angiotensin II induces monocyte chemoattractant protein1 gene expression in rat vascular smooth muscle cells. Circ. Res. 83:952-959.

47. Hernandez-Presa, M., et al. 1997. Angiotensin-converting enzyme inhibition prevents arterial nuclear factor-B activation, monocyte chemoattractant protein-1 expression, and macrophage infiltration in a rabbit model of early accelerated atherosclerosis. Circulation. 95:1532-1541.

48. Boring, L., et al. 1997. Impaired monocyte migration and reduced type 1 (Th1) cytokine responses in C-C chemokine receptor 2 knockout mice. J. Clin. Invest. 100:2552-2561.

49. Carr, M.W., Roth, S.J., Luther, E., Rose, S.S., and Springer, T.A. 1994. Monocyte chemoattractant protein 1 acts as a T-lymphocyte chemoattractant. Proc. Natl. Acad. Sci. USA. 91:3652-3656.

50. Ross, R. 1993. The pathogenesis of atherosclerosis: a perspective for the 1990s. Nature. 362:801-809.

51. Ylä-Herttuala, S., et al. 1991. Expression of monocyte chemoattractant protein-1 in macrophage-rich areas of human and rabbit atherosclerotic lesions. Proc. Natl. Acad. Sci. USA. 88:5252-5256.

52. Gu, L., et al. 1998. Absence of monocyte chemoattractant protein-1 reduces atherosclerosis in low density lipoprotein receptor-deficient mice. Mol. Cell. 2:275-281.

53. Gosling, J., et al. 1999. MCP-1 deficiency reduces susceptibility to atherosclerosis in mice that overexpress human apolipoprotein B. J. Clin. Invest. 103:773-778.

54. Boring, L., Gosling, J., Cleary, M., and Charo, I.F. 1998. Decreased lesion formation in CCR2 (-/-) mice reveals a role for chemokines in the initiation of atherosclerosis. Nature. 394:894-897.

55. Kranzhofer, R., Browatzki, M., Schmidt, J., and Kubler, W. 1999. Angiotensin II activates the proinflammatory transcription factor nuclear factor-B in human monocytes. Biochem. Biophys. Res. Comm. 257:826-828.

56. Carrell, T.W., Smith, A., and Burnand, K.G. 1999. Experimental techniques and models in the study of the development and treatment of abdominal aortic aneurysm. Br. J. Surg. 86:305-312.

57. Tangirala, R.K., Rubin, E.M., and Palinski, W. 1995. Quantitation of atherosclerosis in murine models: correlation between lesions in the aortic origin and in the entire aorta, and differences in the extent of lesions between sexes in LDL receptor-deficient and apolipoprotein E-deficient mice. J. Lipid Res. 36:2320-2328.

58. Carmeliet, P., et al. 1997. Urokinase-generated plasmin activates matrix metalloproteinases during aneurysm formation. Nat. Genet. 17:439-444.

59. Nishijo, N., et al. 1998. Salt-sensitive aortic aneurysm and rupture in hypertensive transgenic mice that overproduce angiotensin II. Lab. Invest. 78:1059-1066.

60. Takenaka, K., et al. 1998. Angiotensin I-converting enzyme gene polymorphism in intracranial saccular aneurysm individuals. Neurol. Res. 20:607-611.

61. Huang, W., Alhenc Gelas, F., and Osborne-Pellegrin, M.J. 1998. Protection of the arterial internal elastic lamina by inhibition of the reninangiotensin system in the rat. Circ. Res. 82:879-890.

62. Mahley, R.W. 1988. Apolipoprotein E: cholesterol transport protein with expanding role in cell biology. Science. 240:622-630.

63. Daughtery, A., and Cassis, L.A. 1999. Chronic angiotensin II infusion promotes atherogenesis in low density lipoprotein receptor -/- mice. Ann. NY Acad. Sci. 892:108-118. 